\title{
Design and Development of Colour Optic Sensor for Robots (COSBOT)
}

\author{
Abu Bakar Ibrahim, Ahmad Rakimi Mohamad, Marzuki Hussain, \\ Ramli Awang Nor, and Razali Ariffin
}

\begin{abstract}
This paper presents the design and development of the Colour Optic Sensor for Robots (COSBOT). The purpose of this project is to create educational projects for all students in the world for learning and teaching image processing concepts. The original idea comes from a game called HuroCup. The following rules and regulations are general rules of HuroCup, a robotic game and robotics benchmark problem for humanoid robots. The HuroCup competition emphasizes the development of flexible, robust, and versatile robots that can perform many different tasks in different domains. HuroCup encourages research into the many areas of humanoid robotics, especially walking and balancing complex motion planning, and humanrobot interaction. There is an all-around competition for the single robot that performs best overall events. Our project prediction is to open all minds that this robot can move according to any direction given using image processing. Before the pixy camera is involved, image processing to robots is difficult because they must have many tons of equipment for processing. This project will be solved what kind of device to create image processing at a fast rate.
\end{abstract}

Keywords - Arduino, Optic Sensor, Pixy Camera.

\section{INTRODUCTION}

Nowadays, technology runs over the world. Begin with the smartphone technology to 'human robotic' technology. Our project is about to create one robotic multifunctional that can detect things. This robotic is called COSBOT. The development for students learns about image sensors and also understanding the motion of robotics. These robots create using a microcontroller board, image sensor and motor driver [1]. This robot can detect the colour items and it will move forward to the colour item according to their coding using $\mathrm{C}$ language. Our main reason for this project is to create a new facility in industry commercial. This is for replacing workers in the industry for quality, efficiency, and effectiveness also for achieving a good number of productions. This robot uses a vision called CYMK colour that detects colour. They can detect 7 colours. This colour may be the one inventor that can change the world. The movement detect which colour we set up and send the data through the microcontroller. Then, the microcontroller sends the data to create a movement in the motor driver. As an objective for our project, we want to create a robot that can detect images by using a camera. Our robot is a special robot that builds with a pixy camera, microcontroller, and motor driver. This robot can detect 7

Submitted on January 20, 2022.

Published on February 14, 2022.

Abu Bakar Ibrahim, Universiti Pendidikan Sultan Idris, Malaysia.

(corresponding e-mail: bakar@fskik.upsi.edu.my)

Ahmad Rakimi Mohamad, Politeknik Ungku Omar, Malaysia.

(e-mail: rakimi@puo.edu.my) types of colours, so we name it COSBOT [2],[3]. We decide to build this robot because we think that a machine with a camera is better to detect objects compare with a normal sensor that is commonly used in all machines nowadays. We choose pixy because its size is small, fast, easy to use, and its cost is standard. Our robot is about the communication between the camera, microcontroller, and motor driver Camera as input and motor driver as an output. First, the pixy camera will detect colour objects, the result will be saved and processed in the image processing area build in the pixy camera. The result will then send to the microcontroller by using SPI/UART language. The microcontroller will save the result and take action based on the program we write in it and send it to the motor driver. The motor driver will forward, backward, pump around or turn left or right. By using this robot, it can replace the sensor of any machine. The sensor can't work well with only 1 or 2 build-in machines because 1 sensor only can detect 1 direction, so the machine needs more than 1 sensor to work well. In this way, our robot can solve the sensors with only 1 camera. Our robot also can help save the cost of a machine. The reason is many sensors in 1 machine is more expensive compared with only 1 pixy camera. Most of the machines in the factory are using sensors, the weakness of sensors is their process is very slow, this is the reason why the speed of production is slow. Using a pixy camera, it and lp solve the machine delay problem because the pixy camera can detect 7 different colour signatures, find hundreds of objects at the same time, and is fast-processing at 50 frames a second. Sometimes the sensors in a machine can't well detect an object because of several problems. But using a camera won't have such a problem because it can detect more clearly than a sensor [4]-[6].

\section{LITERATURE REVIEW}

The project is based on microcontroller board designs, manufactured by several vendors, using various microcontrollers. These systems provide sets of digital and analogue $\mathrm{I} / \mathrm{O}$ pins that can be interfaced to various expansion boards ("shields") and other circuits. The boards feature serial communications interfaces, including USB on some models, for loading programs from personal computers. For programming the microcontroller, the Arduino project provides an integrated development environment (IDE) based

Marzuki Hussain, Politeknik Kota Kuala Terangganu, Malaysia.

(e-mail: marzuki@pkkt.edu.my)

Ramli Awang Nor, Politeknik Jeli Kelantan, Malaysia.

(e-mail: ramli@ pjk.edu.my)

Razali Ariffin, Politeknik Jeli Kelantan, Malaysia.

(e-mail: razali@pjk.edu.my) 
on the Processing project, which includes support for the $\mathrm{C}$ and $\mathrm{C}++$ programming languages [7], [8]. The first Arduino was introduced in 2005, aiming to provide an inexpensive and easy way for novices and professionals to create devices that interact with their environment using sensors and actuators. Common examples of such devices intended for beginner hobbyists include simple robots, thermostats, and motion detectors. Arduino boards are available commercially in preassembled form, or as do-it-yourself kits. The hardware design specifications are openly available, allowing the Arduino boards to be manufactured by anyone. Fig. 1 show the Arduino UNO board [9],[10].

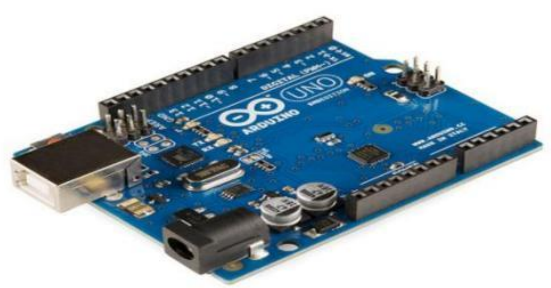

Fig. 1. Arduino UNO Board.

Adafruit Industries estimated in mid-2011 that over 300,000 official Arduino had been commercially produced, and in 2013, 700,000 official boards were in users' hands. Over the years Arduino has been the brain of thousands of projects, from everyday objects to complex scientific instruments. A worldwide community of makers - students, hobbyists, artists, programmers, and professionals - has gathered around this open-source platform, their contributions have added up to an incredible amount of accessible knowledge that can be of great help to novices and experts alike. Arduino was born at the Ivrea Interaction Design Institute (IIDI) as an easy tool for fast prototyping, aimed at students without a background in electronics and programming. As soon as it reached a wider community, the Arduino board started changing to adapt to new needs and challenges, differentiating its offer from simple 8-bit boards to products for IoT applications, wearable, 3D printing, and embedded environments. All Arduino boards are completely open-source, empowering users to build them independently and eventually adapt them to their particular needs. The software, too, is open-source, and it is growing through the contributions of users worldwide [11]-[13].

\section{DESIGN OF COSBOT}

In this section, the project is developed by following the steps as shown step by step from beginning to end. The diagram is shown in Fig. 2 to understand more clearly how COSBOT is produced. The steps are the component placed in one place. They are a pixy camera, Arduino UNO board, motor shield, base robot, servo motor, 9 volts battery and power jack, icsp spi connector also cable connector. Place the Arduino UNO board on the base robot also attach the Arduino UNO board using a steel connector. Attach the pixy camera using an icsp spi connector to send data to the microcontroller. Attach the pixy camera using an icsp spi connector to send data to the microcontroller. Connect $9 \mathrm{v}$ battery to Arduino board. Before that, we have to program the pixy sign and program the Arduino board first. Then, Arduino board and pixy camera connect to a computer to program it [14], [15].

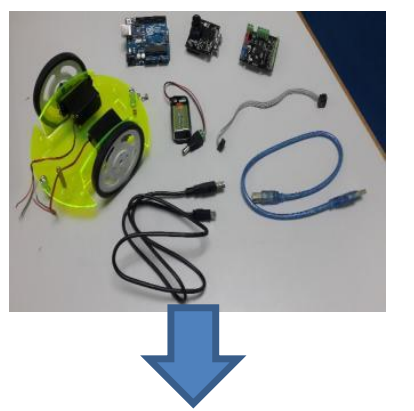

1. The component placed in one place. They are a pixy camera, Arduino UNO board, motor shield, base robot, servo motor, $9 \mathrm{v}$ battery and power jack, icsp spi connector also cable connector.

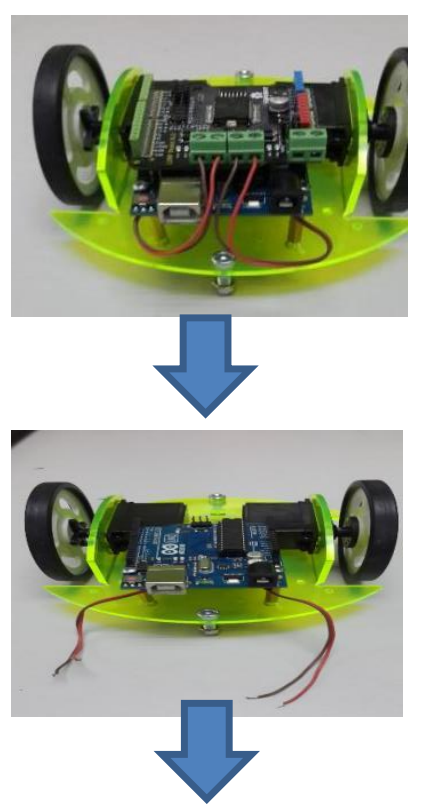

2. Place the Arduino UNO board on the base robot also attach the Arduino UNO board using a steel connector.

3. Then, attach the motor shield to the Arduino UNO board. Connect the wire of the motor to the motor shield according to their polarity.

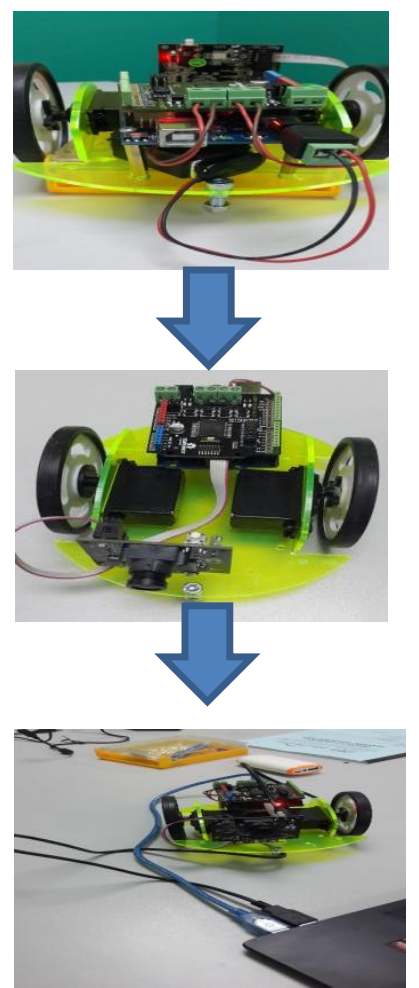

4.Attach the pixy camera using an icsp spi connector to send data to the microcontroller.

5. Connect 9 volts battery to Arduino board. Before that, we have to program the pixy sign and program the Arduino board first.

6. Then, Arduino board and pixy camera connect to a computer to program it. 


\section{RESULT}

Table I shows, the object will follow by the robot based on where the object going. In this result, the robot follows where the object going. the data transfer that robot faster than the commercial sensor.

\begin{tabular}{ccc}
\hline COMMAND & OUTPUT & RESULT \\
\hline $\begin{array}{c}\text { Tracking 1 } \\
\text { Colour (Red) }\end{array}$ & $\begin{array}{c}\text { The robot follow where } \\
\text { the colour going }\end{array}$ & $\sqrt{\text { Success }}$ \\
\hline TRIAL & & \\
COMMAND & RESULT & NOTES \\
\hline FORWARD & 1 & $1^{\text {st }}$ Priority \\
REVERSE & 0 & Ignore \\
LEFT & 1 & $2^{\text {nd }}$ Priority \\
STOP & 1 & Ending \\
\hline
\end{tabular}

In this table also, we create 2 objects in one condition and set one condition to trace one object to another object. And result showing in this table. This condition refers to how the robot moves on 2 or more objects at one time also in one vision.

\section{CONCLUSION}

For this project, we have involved robots that can be processed with image sensors just like our eyes. As the result, this robot has the potential to use in industry commercials. For this project, we have mainly concentrated our project must be functional and can make improvements for these robots. This robot can be used in the industry also in education for diploma students. This project has benefits for industry commercials. We can conclude that we have managed to achieve our objectives in the project by getting the robot controlled by android and microcontroller. We managed to get input about the image sensor using pixy cmucam5. The component is the microcontroller which is Arduino UNO. It is the control centre of the entire system. It contains all the software designs for our project. The microcontroller will receive the movement of these robots and they can think for what the next step. For this project, we have involved robots that it can be throughout the completion of this project, communication between camera, microcontroller and motor driver can be learned and using pixy camera can help solve any machine delay problem as pixy camera can detect 7 different colour signatures, find hundreds of objects at the same time and is processing fast on 50 frames per second. In the future, if given the chance, the right time is given, we are ready to explore more deeply into the world of communication between pixy and robots. In the future, we might explore getting 3 signatures to make our COSBOT respond to our simulations.

\section{REFERENCES}

[1] Yousif J. Social and Telepresence Robots a future of teaching. Artificial Intelligence \& Robotics Development Journal, 2021:58-65.

[2] Development and implementation of a sit-to-stand motion algorithm for humanoid robots. Journal of Advances in Technology and Engineering Research, 2017.

[3] Shultz T. and Kuipers B. Cognitive development in humans and developmental robots. Cognitive Development, 2011;26(1):82-85.

[4] Ando N. and Kanzaki R. Using insects to drive mobile robots - hybrid robots bridge the gap between biological and artificial systems. Arthropod Structure \& Development, 2017;46(5):723-735.
[5] M C. P. Development of Colour based Tomato Harvesting Robot. International Journal for Research in Applied Science and Engineering Technology, 2020;8(8):974-975.

[6] Narayan A., Tuci E., Labrosse F. and Mohammed Alkilabi M. A dynamic colour perception system for autonomous robot navigation on unmarked roads. Neurocomputing, 2018;275:2251-2263.

[7] Object Sorting Robot Mechanism on the Basis of Colour, Height and Type (Metal or Non-metal) using Human Voice Input. International Journal of Recent Technology and Engineering, 2019;8(2S4):24-28.

[8] Krishnakumar S., Sneha K. and Reethika A. Review on Sensor based Colour Sorting Robot for Candy Manufacturing. IOP Conference Series: Materials Science and Engineering, 2021;1084(1):012094.

[9] Sukendar I, Arifin B, Addin F. Analysis and Design of Coil Rolling Machines on Robot Solenoids using Macroergonomic Analysis Method and Design (MEAD) and Rapid Entire Body Assessment (REBA) Based on Arduino Microcontroller. International Journal of Education, Science, Technology, and Engineering, 2020;3(2):35-47.

[10] Pramudia M, Salim A, Prasetyo T. Prototype Design of Automatic Anchovy Drying Robot Using Arduino ATmega 2560. Journal of Physics: Conference Series, 2020;1569(3):032076.

[11] Yuliza Y. and Kholifah U. Robot pembersih lantai berbasis arduino uno dengan sensor ultrasonik. Jurnal Teknologi Elektro, 2015;6(3).

[12] Saw K. and Mon L. Design and Construction of Line Following Robot using Arduino. International Journal of Trend in Scientific Research and Development, 2019;3(4):939-941.

[13] Susanti E. Desain sistem gerak robot quadruped berbasis arduino menggunakan blueetooth hc-05. Sigma Teknika, 2019;2(1):20.

[14] Cheng C., Li S. and Kadry S. Mind-Wave Controlled Robot: An Arduino Robot Simulating the Wheelchair for Paralyzed Patients. International Journal of Robotics and Control, 2018;1(1):6.

[15] KK V. and S S. Industry Monitoring Robot using Arduino Uno with Matlab Interface. Advances in Robotics \& Automation, 2016;05(02).

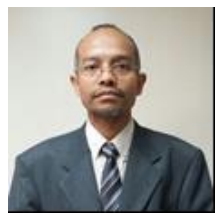

Abu Bakar Ibrahim is an Associate Professor in the Computing Department, Faculty of Arts, Computing and Creative Industry at Sultan Idris Education University, Malaysia. He is received a B.Sc. in Electrical Engineering and a Master's Degree from Universiti Teknologi Malaysia (UTM) in 1998 and 2000, respectively. In 2013, he received a PhD from Universiti Teknikal Malaysia Melaka (UTeM) in Electronic Engineering (Communication). He has professional teaching experience in Low Noise Amplifier (LNA) development, R.F. Communication System, Instructional Technology, Engineering Mathematics, Wireless Communication, and Engineering Education.

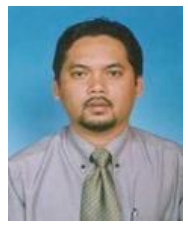

Ahmad Rakimi Mohamad is a Lecturer in Ungku Omar Polytechnic. He is received a B.Sc. in Electrical Engineering and a Master's Degree from Universiti Teknologi Malaysia (UTM) in 1998 and 2000, respectively. In 2013. He has professional teaching experience in Embedded Robotic and microcontroller programming.

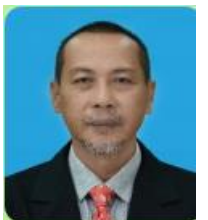

Marzuki Hussain is senior lecturer in Politeknik Kuala Terengganu. He is received a B.Sc. in Electrical Engineering and master of education fromTeknologi Malaysia (UTM) in 1998 and 2000, respectively. In the direction of enhancing innovative creativity in Engineering, Science \& Technology, he has built self-assurance and interest in research and teaching fields. He has professional teaching experience and take variuos position such head of electrical Department conduct various activities realate to certificatte of profesional and reseacrh in IR4.0

Ramli Bin Awang Nor is a Lecture in Politeknik Jeli Kelantan in Agriculture Mechanization Equipment. He receive a B.Sc in Electrical Engineering and a Master's Degree from Universiti Teknologi Malaysia (UTM) in 1998 and 2000, respectively. He has professional teaching experience in Engineering Mathematic, electronic, computer networking, IoT system, Arduino hardware programming, drone and solar green energy system.

Razali Bin Ariffin is a Lecture in Politeknik Jeli Kelantan in Agriculture Mechanization Equipment. He receive a B.Sc in Electrical Engineering and a Master's Degree from Universiti Teknologi Malaysia (UTM) in 1998 and 2000, respectively. He has professional teaching experience in electronic communication, electronic, computer networking, IoT system and digital system. 
